Keiko Ohsugi • Keiko Kobayashi • Kohji Itoh

Hitoshi Sakuraba • Norio Sakuragawa

\title{
Enzymatic corrections for cells derived from Fabry disease patients by a recombinant adenovirus vector
}

Received: July 27, 1999 / Accepted: September 16, 1999

\begin{abstract}
Fabry disease is an X-linked inherited metabolic disorder caused by a deficiency of $\alpha$-galactosidase ( $\alpha$-gal), resulting in the accumulation of ceramide trihexoside (CTH) in body fluids and in many organs and tissues. We constructed a recombinant adenovirus with a human $\alpha$-gal cDNA (AxCAG $\alpha$-gal), and transfected this vector to skin fibroblasts from Fabry patients. Transfected cells expressed high amounts of $\alpha$-gal in their cytoplasm, and a high level of $\alpha$-gal activity was detected in the medium. The accumulated $\mathrm{CTH}$ in the fibroblasts disappeared 3 days after infection. The secreted $\alpha$-gal also eliminated the accumulated CTH from uninfected patient's cells. The enzyme may be taken up through mannose-6-phosphate receptors, as the addition of mannose-6-phosphate to the medium completely inhibited the uptake of the enzyme. The infected cells continued to express $\alpha$-gal for more than 10 days. These results suggest that $\mathrm{AxCAG} \alpha$-gal could be used as enzyme replacement gene therapy for Fabry disease.
\end{abstract}

Key words $\alpha$-Galactosidase $\cdot$ Fabry disease $\cdot$ Adenovirus vector $\cdot$ Trihexoside $\cdot$ Gene therapy

\section{Introduction}

Fabry disease is an X-linked inherited glycolipid metabolic disorder resulting from deficient activity of the lysosomal enzyme, $\alpha$-galactosidase (EC.3.2.1.22, $\alpha$-gal). Neutral glycosphingolipids with terminal $\alpha$-gal-linked galactosyl moieties - globotriaosylceramide (ceramide trihexoside

K. Ohsugi · K. Kobayashi · N. Sakuragawa $(\bowtie)$

Department of Inherited Metabolic Disease, National Institute of Neuroscience, National Center of Neurology and Psychiatry, 4-1-1 Ogawahigashi, Kodaira, Tokyo 187-8502, Japan

Tel. +81-42-346-1716; Fax +81-42-346-1746

e-mail: sakuraga@ncnp.gp.jp

K. Itoh $\cdot$ H. Sakuraba

Department of Clinical Genetics, The Tokyo Metropolitan Institute of Medical Science, Tokyo, Japan
[CTH]) - accumulate in the liver, heart, spleen, kidney, and vascular endothelial cells, as well as in the plasma of patients with Fabry disease. Clinical manifestations of the classical phenotype include angiokeratoma, acroparesthesia, and vascular abnormalities of heart and kidneys, from childhood. A mild phenotype with relatively high residual enzyme activity has been reported as an atypical variant (Sakuraba et al. 1990; Nagao et al. 1991; von Scheidt et al. 1991; Ishii et al. 1992). Treatment strategies for Fabry disease are based on the discovery that lysosomal enzymes are exported from normal cells and are taken up by $\alpha$-gal deficient cells (Mapes et al. 1970). To date, infusions of the purified enzyme (Brady et al. 1973; Tsuji et al. 1994) and plasma exchange (Pyeritz et al. 1980) have been used as therapies for this disease, but, unfortunately, stable clinical effects have not been achieved. Other types of treatment have been attempted, including kidney transplantation (Clarke et al. 1972) and fetal liver transplantation (Touraine et al. 1979). Long-term observation is necessary for evaluating these treatments. In recent years, gene therapy has been suggested as a curative therapy for lysosomal diseases. In most gene therapies for Fabry disease, retrovirus vectors have been employed in preclinical studies (Sugimoto et al. 1995; Medin et al. 1996; Ohshima et al. 1997). However, a clinical study has not yet been carried out.

This study describes the construction and employment of a recombinant adenovirus vector to ameliorate the enzymatic defect in skin fibroblasts derived from patients with Fabry disease. Cells engineered to overexpress $\alpha$-gal were also found to secrete large amounts of $\alpha$-gal. We found that this enzyme was taken up by the uncorrected cells of patients through mannose-6-phosphate (Man-6-P) receptors.

\section{Materials and methods}

Vector construction

The adenovirus vector, AxCAG $\alpha$-galactosidase (AxCAG $\alpha$-gal) was constructed by the Miyake method (Miyake et al. 
1996). Adenoviruses lacking the $\mathrm{E} 1$ region of their genome are replication-incompetent and are grown in the complementary human embryonic kidney 293 cell line. 293 cells are primary human embryonic kidney cells, transformed by sheared human adenovirus type 5 DNA. A pAx1CAwt cosmid was created from the human adenovirus type 5 (Ad5) genome from which the E1a, E1b, and E3 regions were deleted and replaced with an expression unit containing the CAG promoter, composed of the cytomegalovirus enhancer plus the chicken $\beta$-actin promoter, a Swa I site, and the rabbit $\beta$-globin polyadenylation signal. Human $\alpha$ gal cDNA was prepared from cultured lymphoblasts, synthesized and amplified by reverse transcription polymerase chain reaction (RT-PCR) in accordance with the Okumiya method (Okumiya et al. 1995).

\section{Cell culture}

Skin fibroblasts were obtained from patients with Fabry disease. The cells were suspended in Dulbecco's modified Eagle's medium (DMEM) supplemented with 10\% fetal calf serum (FCS), L-glutamine, $100 \mathrm{U} / \mathrm{ml}$ penicillin, and $100 \mu \mathrm{g} / \mathrm{ml}$ streptomycin, and cultured in a $35-\mathrm{mm}$ petri dish in a humidified $5 \% \mathrm{CO}_{2}$ atmosphere at $37^{\circ} \mathrm{C}$.

Fibroblasts from normal volunteers (normal controls) and Fabry patients were infected with AxCAG $\alpha$-gal at varying multiplicity of infection (MOI). Mock-infected cells were infected with adenovirus vector without transfer gene at an MOI of 50. $\alpha$-Gal activity, as well as $\beta$-hexosaminidase activity, was measured in cells cultured for 3 days after infection.

\section{Enzyme assay}

After centrifugation at 5,000 rpm for $5 \mathrm{~min}$, the clear medium was stored at $-20^{\circ} \mathrm{C}$ until assay. The cells were harvested by scraping with a rubber policeman, washed with phosphatebuffered saline (PBS), centrifuged, and stored as pellets at $-20^{\circ} \mathrm{C}$ until assay. The frozen pellets were thawed and agitated with distilled water, using a Vortex mixer (Scientific Industries, Bohemia, NY, USA). The mixture was sonicated three times for 20 s each time, on ice and frozen and thawed three times. These suspensions were assayed as cell extracts.

$\alpha$-Gal activity was determined using 4-methylumbelliferyl- $\alpha$-D-galactopyranoside as the substrate in the presence of $\mathrm{N}$-acetyl-galactosamine, an inhibitor of $\mathrm{N}$ acetylgalactosaminidase, by the Mayes method (Mayes et al. 1981). In addition, $\beta$-hexosaminidase activity (Tallman et al. 1974) was measured, using cell extracts and media as an enzyme control. Protein concentration was determined by Lowry's method (Lowry et al. 1951).

\section{CTH immunofluorescence staining}

According to the Itoh method (Itoh et al. 1993), fibroblasts (1 $\times 10^{4}$ ) were cultured on cover slips (LAB-Tek chamber slide; Nunc, Naperville, IL, USA), infected with AxCAG $\alpha$-gal. After being cultured, cells were fixed with $2 \%$ paraformalde- hyde on ice, then washed three times with PBS, blocked for nonspecific binding with bovine serum albumin, and treated with monoclonal mouse IgG anti-CTH (Kotani et al. 1992) as a first antibody and with fluorescein isothiocyanate (FITC)conjugated $\mathrm{F}(\mathrm{ab})_{2}$ gout anti-mouse IgG as a second antibody. The stained cells were examined with a Bio-Rad MRC-600 confocal laser scanning microscope (Bio-Rad, Hemel Hempstead, UK) attached to a Nikon microscope (Optiphot 2; Nikon, Tokyo, Japan).

Uptake and secretion studies

In fibroblasts, lysosomal enzymes may be transported from the extracellular space to lysosomes through receptormediated endocytosis. The uptake of the secreted enzymes was almost completely blocked when Man-6-P was added to the incubation medium indicating that the uptake was mediated through the Man-6-P receptors on these cells. One-mM Man-6-P has usually been employed for uptake studies of the secreted enzyme (Medin et al. 1996). Accordingly, the cells were cultured in medium containing $1 \mathrm{mM}$ Man-6-P, followed by immunofluorescence staining to detect accumulated $\mathrm{CTH}$ in the cells.

\section{Results}

\section{Adenovirus construct}

The recombinant adenovirus Ax CAG $\alpha$-gal construct is shown in Fig. 1. We tested the ability of AxCALacZ (recombinant adenovirus with inserted Escherichia coli LacZ gene) to infect the fibroblasts. The cells were infected with AxCALacZ at an MOI of 5, 20, and 50. About 6.6\%, 33\%, and $80 \%$ of the cells were positive for $\beta$-gal activity at an MOI of 5, 20 and 50, respectively.

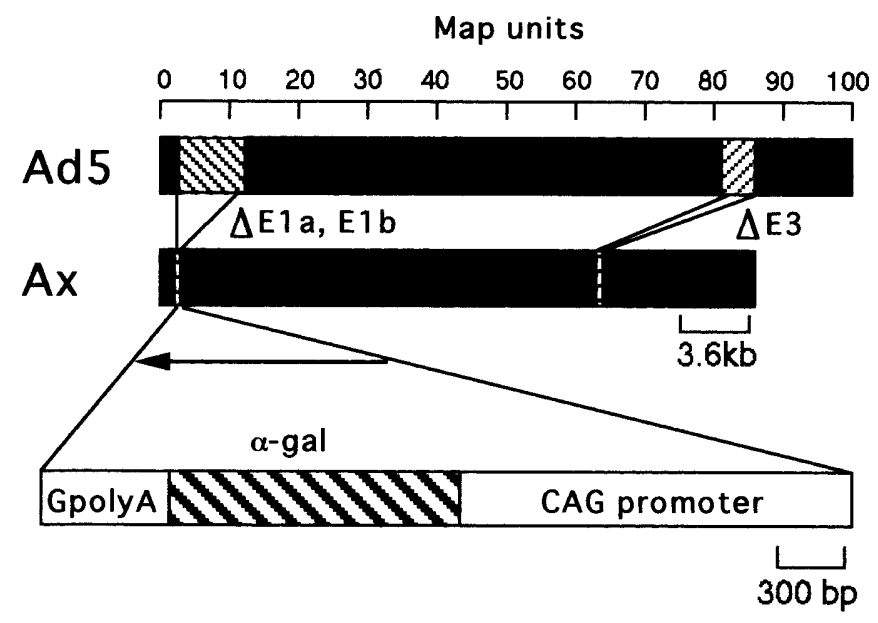

Fig. 1. Construct of the recombinant adenovirus vector (AxCAG $\alpha$ gal). AxCAG $\alpha$-gal was constructed by inserting the human $\alpha$-gal cDNA and CAG promoter into human adenovirus type 5 genomes with deleted E1a, E1b, and E3 regions 
Enzymatic correction of cells from patients with Fabry disease

$\alpha$-Gal activity in Fabry fibroblasts was less than $10 \%$ that of normal controls; $14.7 \pm 5.9$ (normal controls) and $0.5 \pm$ $0.3 \mathrm{nmol} / \mathrm{mg}$ per $\mathrm{h}$ (patients). The $\beta$-hexosaminidase activity of the cells was within normal limits; $470.3 \pm 162.5$ (normal controls), and $461.3 \pm 119.4 \mathrm{nmol} / \mathrm{mg}$ per $\mathrm{h}$ (patients). The cells infected with AxCAG $\alpha$-gal showed greatly increased $\alpha$ gal activity depending on MOI (Fig. 2). $\alpha$-Gal transfected cells (MOI 5) had $\alpha$-gal activity ten times higher than the normal control levels. No increase in $\alpha$-gal activity was observed in the mock-infected cells (Fig. 3). $\beta$ Hexosaminidase activity was not affected under these conditions.

Immunostaining with CTH antibody is shown in Fig. 4. In the cells from Fabry patients, strong fluorescence was detected, while fluorescence was scarcely detected in normal subjects (Fig. 4A,B). The accumulated CTH in Fabry fibroblasts decreased after infection with AxCAG $\alpha$-gal and was inversly proportional to MOI (Fig. 4C,D).

\section{Secretion studies}

To determine whether extracellular secretion of $\alpha$-gal occurred in the corrected cells, the cells from Fabry patients were infected with AxCAG $\alpha$-gal at an MOI of 50 and were cultured in DMEM with 5\% FCS to suppress cell growth. The $\alpha$-gal activity in cells and medium was measured for 10 days. The enzyme activity was assayed on day 3 after the medium was changed. $\alpha-\mathrm{Gal}$ activity in the cells increased for 7 days and remained at a high level. The enzyme activity in the medium also increased, similarly to findings in the cells (Fig. 5).

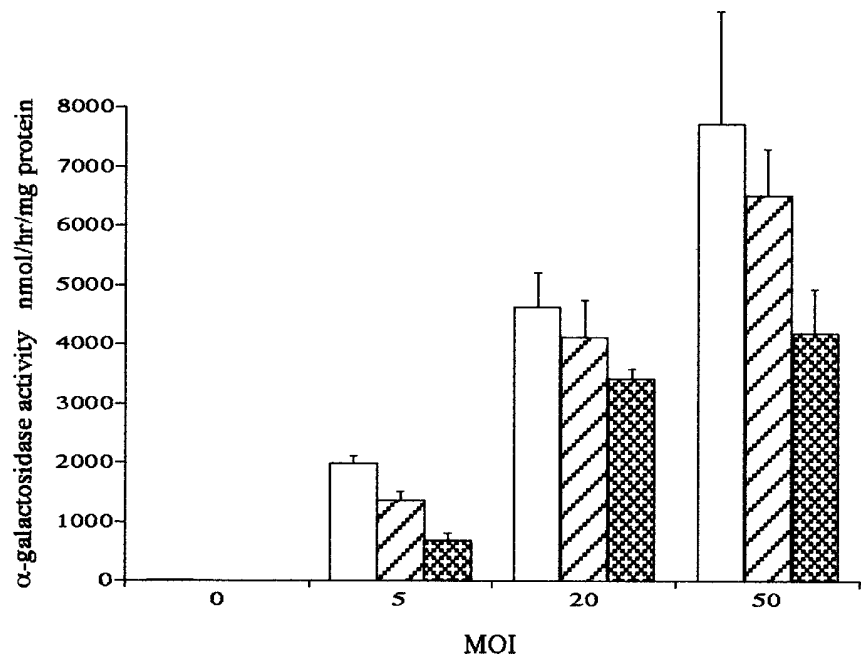

Fig. 2. $\alpha$-Galactosidase (gal) activity in fibroblasts infected with AxCAG $\alpha$-gal. Fibroblasts from normal volunteers (control) and patients with Fabry disease were infected with AxCAG $\alpha$-gal at various multiplicity of infection $(M O I), \alpha-\mathrm{Gal}$ activity was determined on day 3 after infection. $\alpha$-Gal activity in uninfected cells was $15.5 \pm 3.8$ (control; white bars), $1.2 \pm 0.4$ (patient 1 ; diagorally cross-hatched bars), and $0.7 \pm 0.2 \mathrm{nmol} / \mathrm{h}$ per $\mathrm{mg}$ (patient 2 , criss-crossed bars)
Uptake studies

The uptake of the secreted enzyme by non-treated cells from Fabry patients was examined by immunostaining. Cells were cultured in normal medium for 6 days, and showed extensive accumulation of CTH (Fig. 6A). The cell culture with medium containing secreted $\alpha$-gal showed markedly decreased CTH accumulation in Fabry cells (Fig. $6 \mathrm{~B} ; 25 \%$, Fig. $6 \mathrm{C} ; 50 \%$ of medium containing secreted $\alpha$ gal). The addition of $1 \mathrm{mM}$ Man-6-P to the medium containing secreted $\alpha$-gal suppressed the removal of CTH

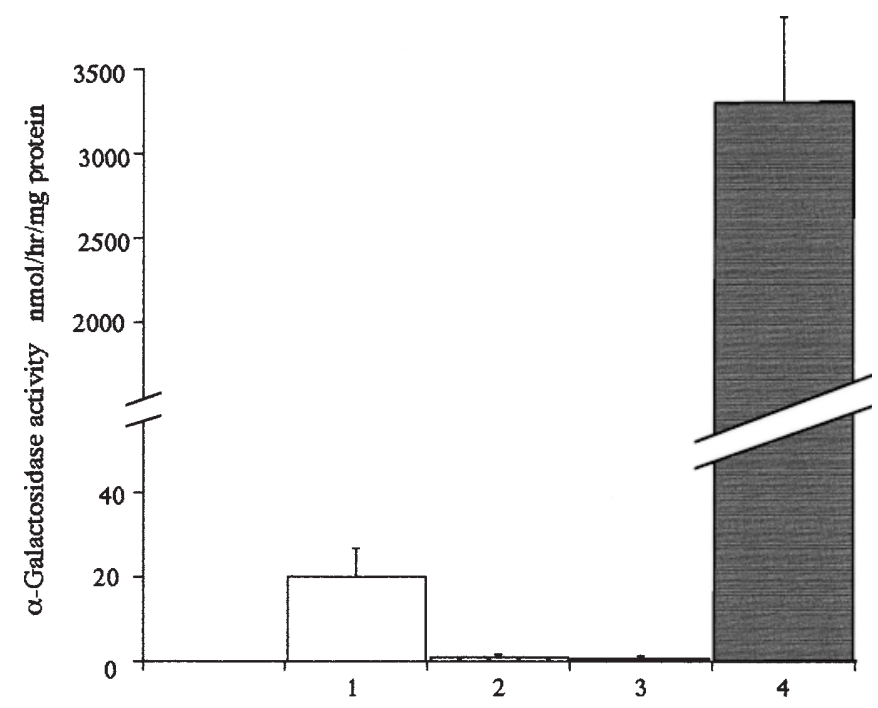

Fig. 3. Correction of enzymatic defect in fibroblasts from Fabry patients. Mock-infected cells were infected at an MOI of 20 and corrected cells were infected at an MOI of 5. 1, White bar, Control fibroblasts; 2, patient fibroblasts; 3, patient fibroblasts, mock-infected; 4, black bar, patient fibroblasts AxCAG $\alpha$-gal-infected
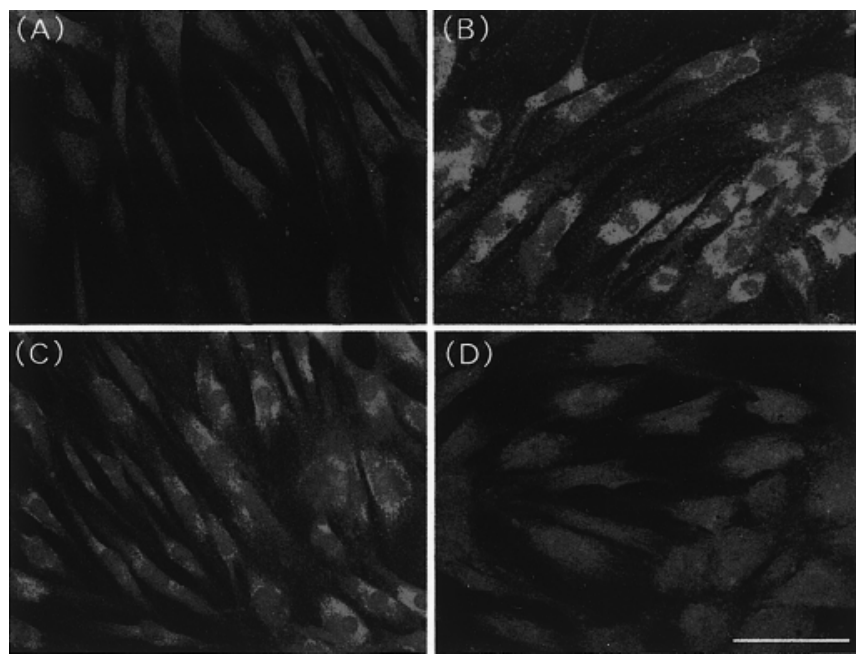

Fig. 4A-D. Immunostaining for ceramide trihexoside (CTH) in Fabry fibroblasts infected with AxCAG $\alpha$-gal. Fixation and immunostaining were performed after day 3 of infection. A Non-treated cells from a control subject. B Non-treated cells from a patient. C Infected cells from a patient at an MOI of 20. D Infected cells from a patient at an MOI of 50. Scale bar, $100 \mu \mathrm{m}$ 


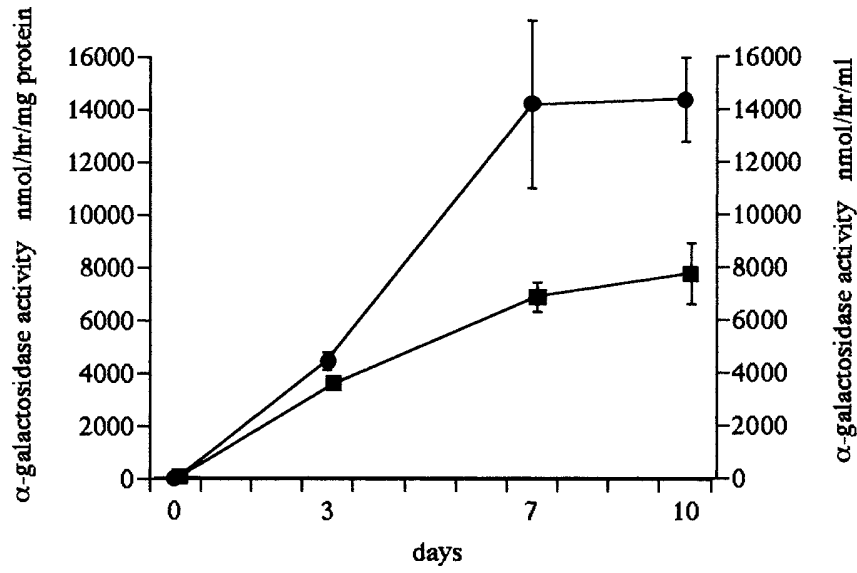

Fig. 5. $\alpha$-Gal activity of medium with time (squares) and the enzyme activity in cells (closed circles) from a Fabry patient. The infected cells from the patient were cultured in medium supplemented with $5 \%$ fetal calf serum. The medium was changed every 3 or 4 days. Enzyme activity was assayed on day 3 after medium was changed. Left bar indicates enzyme activity in cells (nmol/mg per $\mathrm{h}$ ) and right bar shows enzyme activity in the medium ( $\mathrm{nmol} / \mathrm{ml}$ per $\mathrm{h}$ )
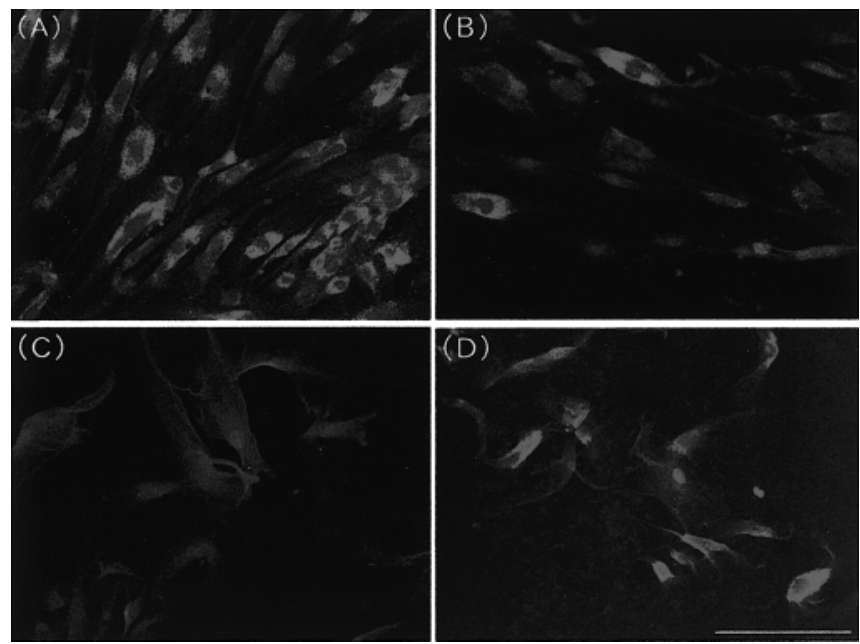

Fig. 6A-D. Immunostaining for CTH in Fabry patient's fibroblasts which had taken up the secreted enzyme. The cells were cultured for 6 days in medium containing a high amount of the secreted enzyme. $\mathbf{A}$ Cells cultured in normal medium. B Cells cultured in medium with $25 \%$ by volume of medium containing the secreted enzyme. C Cell cultured in medium with $50 \%$ by volume of medium containing the secreted enzyme. D Cells cultured in the same medium as that in (C) but including $1 \mathrm{mM}$ mannose-6-phosphate. Scale bar, $200 \mu \mathrm{m}$

accumulation in the Fabry cells (Fig. 6D). This result suggested that the secreted enzymes were taken up through the Man-6-P receptors.

\section{Discussion}

In this report, we describe the construction of a recombinant adenovirus vector that engineered efficient transduction and the expression of $\alpha$-gal activity in Fabry cells. This vector eliminated the enzymatic defect in cells obtained from patients with Fabry disease. In addition to the amelioration of the enzyme defect in fibroblasts from the patients, we demonstrated accumulated CTH removal from the uncorrected cells by immunostaining. Further, the transfected cells secreted a high activity of $\alpha$-gal into the medium, which was taken up by the uncorrected cells in a Man-6-P receptor-specific manner, resulting in the correction of accumulated CTH.

Treatment of Fabry disease has been based on $\alpha$-gal supplement action. Initially, enzyme therapy was attempted by infusing normal human plasma (Mapes et al. 1970), but results were limited because of the low level of enzyme activity present, the rapid clearance of the infused enzyme, and the hazards of repeated plasma transfusions. Intravenous infusion of purified human $\alpha$-gal briefly reduced plasma CTH levels (Brady et al. 1973; Desnick et al. 1979). Plasma exchange has also been attempted (Pyeritz et al. 1980). But these treatments have not achieved stable clinical effects. Other attempts were made, including transplantation of kidney (Clarke et al. 1972) and fetal liver (Touraine et al. 1979). Long-term observation is necessary for deciding the feasibility of these methods. Tsuji et al. (1994) was able to deliver the purified enzymes to target cells by using $\alpha_{2}$-macroglobulin as the transport vehicle.

In recent years, gene therapy has been expected to be a curative therapy for lysosomal disease. Gene therapies for Fabry disease have been studied by using retroviruses. Sugimoto et al. (1995) reported the efficient expression of human $\alpha$-gal in NIH3T3 cells, using a bicistronic multidrugresistant gene retrovirus. Medin et al. (1996) described the construction and application of a high-titer recombinant retroviral vector to correct the enzymatic defect in hematopoietic and other cells derived from patients with Fabry disease. Their results were effective for correcting the enzyme deficiency in the cells from these patients in vitro.

A recombinant adenovirus vector has very high titers and can transduce the gene into both divided and undivided cells. Our AxCAG $\alpha$-gal expressed more than 100-fold the $\alpha$-gal activity of an AxCAG $\alpha$-gal infection at an MOI of 5, compared with uninfected cells, although the infection rate was only $6 \%$ at an MOI of 5 . The expression of $\alpha$-gal activity by AxCAG $\alpha$-gal started $24 \mathrm{~h}$ after infection, increased gradually for 7 days, and remained at a high level for more than 10 days. The accumulated CTH in the cells from the patients disappeared 3 days after AxCAG $\alpha$-gal infection at an MOI of 50. $\alpha$-Gal activity was very high in the cells and was secreted extensively into the medium, where this enzyme was taken up by uncorrected cells. It is not clear whether very high $\alpha$-gal activity exerts an influence on cells or tissues. Kase et al. (1998) reported that transgenic mice expressing human $\alpha$-gal had $\alpha$-gal activity of 22 , being approximately 11,080 -fold higher in the liver, kidney, heart, and other tissues of these mice than that in non-transgenic mice. Kase et al. did not describe the clinical disadvantages of the transgenic mice. Ioannou et al. (1996) used enzyme replacement therapy in $\alpha$-gal-deficient mice, with resultant reduction in the substrate levels in plasma, liver, and heart. Ohshima et al. (1997) established $\alpha$-gal gene knockout mice and showed that they were useful as Fabry disease models. 
More recently, they reported that aging accentuated and bone marrow transplantation ameliorated metabolic defects in their knockout mice (Ohshima et al. 1999).

Our data provided compelling evidence that the recombinant adenovirus vector corrected the accumulated substrate, $\mathrm{CTH}$, in fibroblasts from Fabry patients. Judging from the evidence showing the uptake of secreted enzyme, which also decreased $\mathrm{CTH}$, we suggest that our therapeutic system, using recombinant adenovirus, could be employed for cell therapy using genetically modified stem/progenitor cells from normal and Fabry patient donors.

Acknowledgments We thank Dr. Satoru Takahashi for his great help and many suggestions, and Ms. Keiko Kawanishi for assaying the enzymes. This work was supported in part by Health Sciences Research Grants for Research on Brain Science and Research on Advanced Medical Technology.

\section{References}

Brady RO, Tallman JF, Johnson WG, Gal AE, Leahy WR, Quirk JM, Dekaban AS (1973) Replacement therapy for inherited enzyme deficiency. Use of purified ceramidetrihexosidase in Fabry disease. N Engl J Med 289:9-14

Clarke JJR, Guttmann RD, Wolfe LS, Beaudoin JG, Morehouse DD (1972) Enzyme replacement therapy by renal allo-transplantation in Fabry's disease. N Engl J Med 287:1215-1218

Desnick RJ, Dean KJ, Grabowski G, Bishop DF, Sweeley CC (1979) Enzyme therapy in Fabry disease: differential in vivo plasma clearance and metabolic effectiveness of plasma and splenic $\alpha$-galactosidase A isozymes. Proc Natl Acad Sci USA 76:5326-5330

Ioannou YA, Zeidner KM, Friedman B, Desnick RJ (1996) Fabry disease: enzyme replacement therapy in $\alpha$-galactosidase A deficient mice (abstract). Am J Hum Genet 59:15

Ishii S, Sakuraba H, Suzuki Y (1992) Point mutations in exon 6 upstream region of $\alpha$-galactosidase A cause atypical variant of Fabry disease. Hum Genet 89:29-32

Itoh K, Kotani M, Tai T, Suzuki H, Utsunomiya T, Inoue H, Yamada H, Sakuraba H, Suzuki Y (1993) Immuno-fluorescence imaging diagnosis of Fabry heterozygotes using confocal laser scanning microscopy. Clin Genet 44:302-306

Kase R, Shimmoto M, Itoh K, Utsumi K, Kotani M, Taya C, Yonekawa H, Sakuraba H (1998) Immunohistochemical characterization of transgenic mice highly expressing human lysosomal $\alpha$-galactosidase. Biochim Biophys Acta 1406:260-266

Kotani M, Ozawa H, Kawashima I, Ando S, Tai T (1992) Generation of one set of monoclonal antibodies specific for a pathway ganglioseries gangliosides. Biochim Biophys Acta 1117:97-103

Lowry OH, Rosebrough NJ, Farr AL, Randall RJ (1951) Protein measurement with Folin phenol reagent. J Biol Chem 193:265-275
Mapes CA, Anderson RL, Sweeley CC (1970) Enzyme replacement in Fabry disease, an inborn error of metabolism. Science 169:987-989 Mayes JS, Scheerer JB, Sidwea RN, Donaldson ML (1981) Differential assay for lysosomal alpha-galactosidases in human tissues and its application to Fabry's disease. Clin Chim Acta 112:247-251

Medin JA, Tudor M, Simovitch R, Quirk JM, Jacobson, S, Murray GJ, Brady RO (1996) Correction in trans for Fabry disease: expression, secretion and uptake of $\alpha$-galactosidase A in patient-derived cells driven by a high-titer recombinant retroviral vector. Proc Natl Acad Sci USA 93:7917-7922

Miyake S, Makimura M, Kanegae Y, Harada S, Sato Y, Takamori K, Tokuda C, Saito I (1996) Efficient generation of recombinant adenoviruses using adenovirus DNA-terminal protein complex and a cosmid bearing the full-length virus genome. Proc Natl Acad Sci USA 93:1320-1324

Nagao Y, Nakashima H, Fukuhara Y, Shimmoto M, Oshima A, Ikari Y, Mori Y, Sakuraba H, Suzuki Y (1991) Hypertrophic cardiomyopathy in late-onset variant of Fabry disease with high residual activity of $\alpha$-galactosidase A. Clin Genet 39:233-237

Ohshima T, Murray GJ, Swaim WD, Longenecker G, Quirk JM, Cardarelli CO, Sugimoto Y, Pastan L, Gottesman MM, Brady RO, Kulkarni AB (1997) $\alpha$-Galactosidase A deficient mice: a mode of Fabry disease. Proc Natl Acad Sci USA 94:2540-2544

Ohshima T, Schiffmann R, Murray GJ, Kopp J, Quirk JM, Stahl S, Chan CC, Zerfas P, Tao-Cheng J, Ward JM, Brady RO, Kulkarni AB (1999) Aging accentuates and bone marrow transplantation ameliorates metabolic defects in Fabry disease mice. Proc Natl Acad Sci USA 96:6423-6427

Okumiya T, Ishii S, Kase R, Kamei S, Sakuraba H, Suzuki Y (1995) $\alpha$ Galactosidase gene mutations in Fabry disease: heterogeneous expressions of mutant enzyme proteins. Hum Genet 95:557-561

Pyeritz, RE, Ullman MD, Moser AB, Braine HG, Moser HW (1980) Plasma exchange removes glycosphingolipid in Fabry disease. Am J Med Genet 7:301-307

Sakuraba H, Oshima A, Fukuhara Y, Shimmoto M, Nagao Y, Bishop DF, Desnick RJ, Suzuki Y (1990) Identification of point mutations in the $\alpha$-galactosidase A gene in classical and atypical hemizygotes with Fabry disease. Am J Hum Genet 47:784-789

Sugimoto Y, Aksentijevich I, Murray GJ, Brady RO, Pastan I, Gottesman MM (1995) Retroviral coexpression of a multidrug resistance gene (MDR1) and human $\alpha$-galactosidase A for gene therapy of Fabry disease. Hum Gene Ther 6:905-915

Tallman JF, Brady RO, Quirk JM, Villalba M, Gal AE (1974) Isolation and relationship of human hexosaminidase. J Biol Chem 249:34893499

Touraine JL, Malik MC, Tranger J, Perrot H, Maire I (1979) Attempt at enzyme replacement by fetal liver transplantation in Fabry's diease. Lancet I:1094-1095

Tsuji A, Oda R, Sakiyama K, Nagamune H, Itoh K, Kase R, Sakuraba H, Suzuki Y, Matsuda Y (1994) Lysosomal enzyme replacement using $\alpha_{2}$-macroglobulin as a transport vehicle. J Biochem 115:937944

von Scheidt W, Eng CM, Fitzmaurice TF, Erdmann E, Hebner G, Olsen EGJ, Christomanou H, Kandolf R, Bishop DF, Desnick RJ (1991) An atypical variant of Fabry's disease with manifestations confined to the myocardium. N Engl J Med 24:395-399 